\title{
Analysis on Consumption Trend and Forecast of the Chinese Fruit Market
}

Lingling Lu*

Anyang Normal University, Anyang, China, 455000

*Corresponding Author

Lingling Lu

\section{Article History}

Received: 05.05.2020

Accepted: 12.05.2020

Published: 16.05.2020

\begin{abstract}
It is of great significance to establish relevant models by collecting data of various fruit production through the network, to screen out the main fruit varieties in the fruit market of China in recent years, to predict the consumption and production trend of the Chinese fruit market, and to plan the planting mode of fruit scientifically. Based on the data collected, this paper makes use of Lingo software to cluster and classify fruits, then establishes 0-1 programming model and time prediction model to predict data and test by regression model. Finally, the development strategy of fruit production in China is given.

Keywords: The Chinese fruit market, cluster analysis, 0-1 programming, time series prediction model.
\end{abstract}

\section{INTRODUCTION}

With the gradual improvement of living standards, while people pay attention to their health, they also gradually increase their requirements for daily diet. Fruit contains most of the nutrients needed by the human body. Eating more fruits daily can not only keep the body healthy and improve the body immunity, but also play an important role in reducing chronic diseases. Since 1979, the planting area and yield of fruit in China have increased rapidly, and the variety of fruit has become increasingly abundant. At present, there are still many studies on the consumption trend of the Chinese fruit market.

Based on the current situation of Chinese fruit and vegetable production, the gray model which can be used to predict the consumption of fruit and vegetable was established by Song and Wang in [1]. Based on the consumption data of apple and spinach from 2003 to 2009, they predicted the consumption of 16 fruits and vegetable major from 2015 to 2020, and analyzed the different types of fruit and vegetable consumption in the development trend of the next six years. From the perspective of human dietary balance, Liu et al. studied the consumption trend and structure optimization of fruits and vegetables in China, and suggested that our government should consider the dietary nutrition balance of human body and the future market nutrition demand in the decision making of fruit and vegetable strategic layout [2]. Based on the human nutrition angle, Song et al. researched reasonable fruit intake, and they also classified the common fruits on the basis of nutrients through the system clustering analysis [3]. Peng and Zhou applied the H-K decomposition method of three margins to decompose the import and export of the whole fruit and sub-fresh frozen and processed fruit from 2002 to 2017 to provide a empirical explanation based on the growth path for the changes of china's fruit trade [4]. However, for a long time, the unhealthy habits of Chinese residents, such as not eating, partial to eat, eating too much, etc., neglecting the nutritional balance required for human health, which makes the fruit consumption blind and disorderly and greatly affects the production of fruit. Therefore, it is of great significance to predict the consumption and production trends of the Chinese fruit market.

This paper explores the consumption trend and forecast of Chinese fruit market with reference to all kinds of relevant materials and research literature, so that readers can have a deeper understanding of the consumption trend and structure optimization of the Chinese fruit market. This paper is composed of the following three parts: first, to establish

Copyright @ 2020: This is an open-access article distributed under the terms of the Creative Commons Attribution license which permits unrestricted use, distribution, and reproduction in any medium for non commercial use (NonCommercial, or CC-BY-NC) provided the original author and source are credited. 
a 0-1 planning model to know the main fruit varieties in the Chinese fruit market in recent years through appropriate methods; the second is to use the time series model to analyze the consumption trends of the Chinese fruit market, and to test with a polynomial regression prediction model to obtain reasonable forecast data; the third is to establish a product of our residents, and accordingly put forward the strategy of fruit production in China.

\section{METHODS}

\section{The main fruit varieties in the Chinese fruit market in recent years}

Screening the main fruit varieties, the main fruit first has an advantage in yield, should meet certain yield requirements, that is, the total yield of the main fruit should be relatively large. Therefore, to collect the common types of fruit to count the annual output of fruit, the selection of the main fruit yield at least $80 \%$ of the total output of fruit, and then should have to meet the nutritional and health needs of the human body. From the point of view of nutrition and health, the selected fruits and people's daily dietary experience (nutritional composition of fruit and dietary nutrients reference daily intake of Chinese residents) were clustered to obtain the possible main fruits.

Once again, from the point of view of universality, some kind of fruit selection and non-selection can be considered when screening. Therefore, it can be regarded as a goal planning problem, that is, it can establish a model related to the problem of target selection. The screening criteria need to be determined, followed by a $0-1$ programming model. Then the model is solved by appropriate method, and the main fruit is obtained.

To collect the actual situation of the Chinese fruit market in recent years for data analysis, it is required to screen out the main fruit varieties. The data collected should be as comprehensive and reliable as possible. By querying the data in the Plant Management Department of the Ministry of Agriculture of the People's Republic of China and combining the data in the nutritional composition table of common fruits in life, the data is relatively complete. In order to facilitate the screening of fruits, we selected the yield of these common fruits such as apples, pears and citruses from 2006 to 2016. The data collection results of fruits are shown in Table 1.

Table-1: Fruit yield from 2006 to 2016 (Unit: 10,000 tons)

\begin{tabular}{|l|l|l|l|l|l|l|l|l|l|l|l|}
\hline Fruits & $\mathbf{2 0 0 6}$ & $\mathbf{2 0 0 7}$ & $\mathbf{2 0 0 8}$ & $\mathbf{2 0 0 9}$ & $\mathbf{2 0 1 0}$ & $\mathbf{2 0 1 1}$ & $\mathbf{2 0 1 2}$ & $\mathbf{2 0 1 3}$ & $\mathbf{2 0 1 4}$ & $\mathbf{2 0 1 5}$ & $\mathbf{2 0 1 6}$ \\
\hline Apple & 2605.9 & 2786 & 2984.7 & 3168.1 & 3326.3 & 3598.5 & 3849.1 & 3968.3 & 4092.3 & 4261.3 & 4388.2 \\
\hline Pear & 1198.6 & 1289.5 & 1353.8 & 1426.3 & 1505.7 & 1579.5 & 1707.3 & 1730.1 & 1796.4 & 1869.9 & 1870.4 \\
\hline Citrus & 1789.8 & 2058.3 & 2331.3 & 2521.1 & 2645.2 & 2944 & 3167.8 & 3320.9 & 3492.7 & 3660.1 & 3764.9 \\
\hline Banana & 690.12 & 779.67 & 783.47 & 883.39 & 956.05 & 1040 & 1155.8 & 1207.5 & 1179.2 & 1246.6 & 1299.7 \\
\hline Pineapple & 89.07 & 90.509 & 93.363 & 104.26 & 107.6 & 119.11 & 128.71 & 138.64 & 143.27 & 149.54 & 158.2 \\
\hline Litchi & 150.8 & 170.77 & 150.73 & 169.56 & 177.39 & 189.72 & 190.69 & 202.25 & 225.97 & 230.79 & 229.61 \\
\hline Longan & 110.77 & 116.97 & 127.06 & 125.98 & 131.21 & 144.3 & 152.63 & 155.52 & 174.9 & 184.56 & 191.39 \\
\hline Peach & 821.47 & 905.18 & 953.44 & 1004 & 1045.6 & 1098.3 & 1143 & 1192.4 & 1287.4 & 1364 & 1428.9 \\
\hline Kiwi & 52.319 & 57.847 & 67.398 & 87.513 & 106.98 & 125.54 & 145.28 & 176.58 & 202.28 & 218.79 & 234.49 \\
\hline Grape & 627.08 & 669.68 & 715.15 & 794.06 & 854.89 & 906.75 & 1054.3 & 1155 & 1254.6 & 1366.9 & 1374.5 \\
\hline Red dates & 305.29 & 303.06 & 363.41 & 424.78 & 446.83 & 542.68 & 588.71 & 634 & 734.53 & 807.58 & 824.05 \\
\hline Persimmon & 232.03 & 257.41 & 271.1 & 283.42 & 0 & 318.72 & 341.76 & 353.88 & 373.08 & 379.14 & 396.91 \\
\hline
\end{tabular}

Observing the above table, it is found that the collected data is not comprehensive. We can see that the yield of persimmon in 2010 is 0 , and the data is missing, so we need to process the missing data. Considering all kinds of conditional factors, the missing data are filled by means of mean value here, and the result is 3.050534 million tons.

Use cluster analysis to screen and solve the main fruits. For the analysis of the nutrient composition of common fruits, considering the similarity of the nutrient elements of the main fruits, fruits with similar nutrient composition are divided into one category, and cluster analysis is used to classify similar things into one category for analysis. For data processing, we use Spss software to import data, and then click to analyze the classification. Through cluster analysis, the 36 common fruits we collected can be divided into 6 categories. The specific analysis results are as follows: first category: mango, second category: kiwi, third category: banana, coconut, durian, fourth category: jujube, fifth category: oranges, sixth category: apples, cantaloupe, grapes and pears and the remaining 29 kinds of fruits.

On the basis of the above preparation, it is reasonable to set the total output of selected fruits up to $80 \%$ of the total annual output on the basis of considering the selection and non-selection. At the same time, set the selected fruit contains as many nutrients as possible as the objective function. The main screening models based on 0-1 programming are as follows:

$$
a_{i}=\left\{\begin{array}{l}
0, i \text {-th fruit is not sleelected, } \\
1, i \text {-th fruit is sleelected, }
\end{array}\right.
$$




$$
b=\sum a_{i} M_{i} \geq 80 \%, c=\operatorname{Max} \sum \sum a_{i} x_{i j}, i=1,2,3, \cdots, n, j=1,2,3, \cdots, m,
$$

where $M_{i}$ represents the production of the i-th fruit yield as a percentage of the total fruit yield, $b$ is as a constraint condition, $\sum a_{i} M_{i} \geq 80 \%$ indicates that the percentage of selected fruit reaches $80 \%$ of total fruit yield, $c$ is an object function, $\operatorname{Max} \sum \sum a_{i} x_{i j}$ means that the selected fruit contains as many nutrients as possible. The i-th fruit is indicated by $X=\left(x_{1}, x_{2}, \cdots, x_{i}\right), i=1,2, \cdots, m$.

To analyze the data in Table 1, taking the 2015 data as an example, to ensure that the total output of the main fruits exceeds $80 \%$ of their respective total output, the data is processed using the $0-1$ planning model, and the processed results are as follows: One type is banana, the second type is jujube, the third type is kiwi, and the fourth type is apple, pear, citrus, pineapple, litchi, longan, peach, grape, persimmon. Finally, comparing the above two results, it can be seen that the fruit classification and the number of classifications in the second result are less than the number in the first result. This is the final result of 36 common fruits after clustering and 0-1 planning. As the final screening result, there are 12 kinds of fruits screened. The query data shows that the total output of fruit in 2015 was 174,795,700 tons, and a graph of the proportion of main fruit production is made, as shown in Figure 1. It can be seen from the figure that the twelve kinds of fruits are: apple, pear, citrus, banana, pineapple, lychee, longan, peach, grape, kiwi, red date and persimmon.

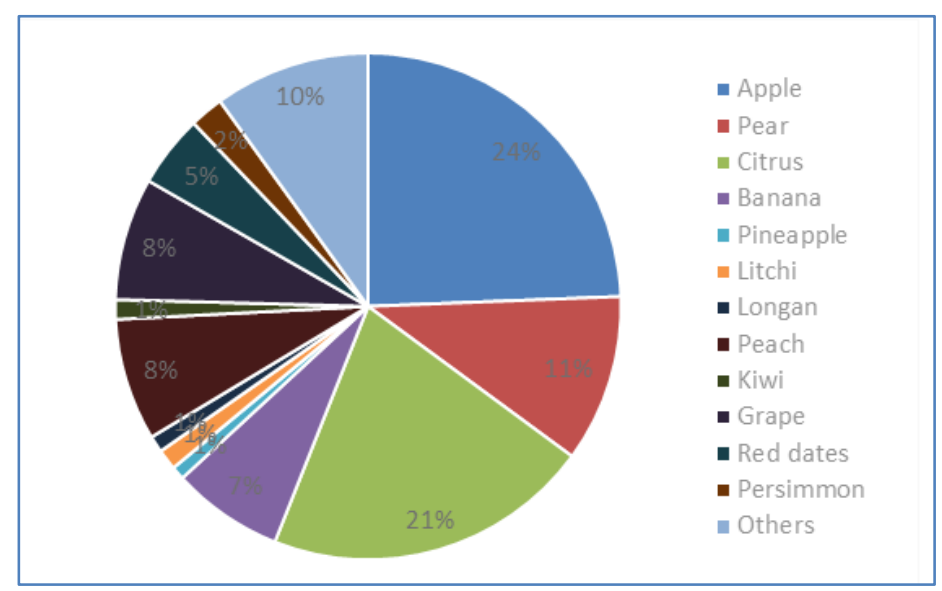

Fig-1: The yield of 12 major fruits as a percentage of the total fruit yield in 2015

In order to test the representativeness and credibility of the results obtained, the percentage of the total output of the main fruit produced in 2011-2016 is determined. The statistical analysis is shown in Figure 2. It can be seen from the figure that the yield of 12 major fruits such as apples, pears, and bananas has accounted for about $90 \%$ of the total fruit yield in recent years, which is quite in line with the selection criteria.

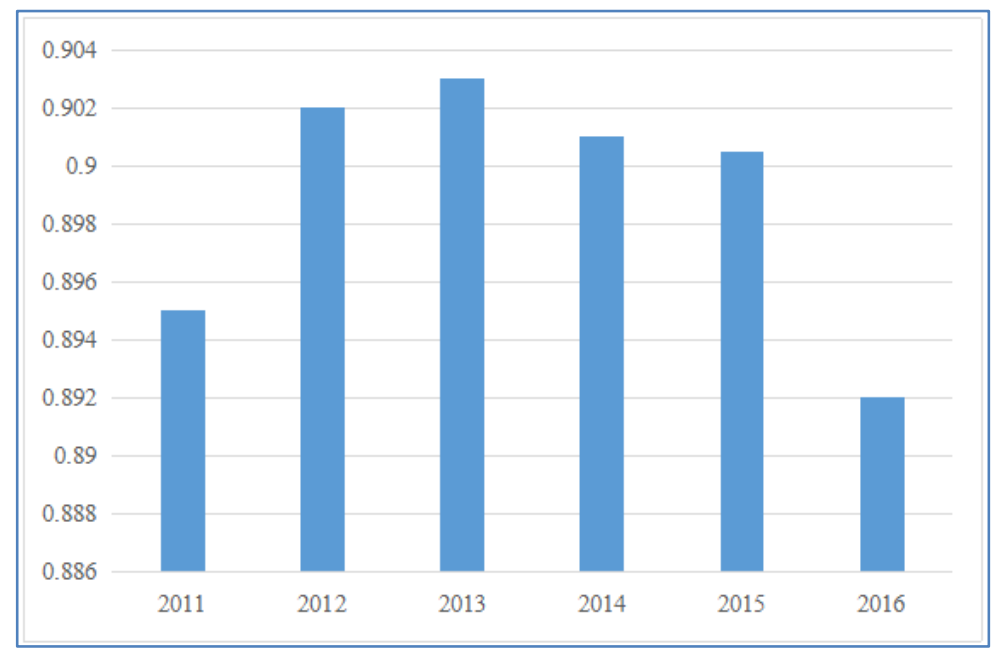

Fig-2: Major fruits as a percentage of total fruit yield from 2011 to 2016 


\section{Consumption Trend of Chinese Fruit Market}

For the prediction of fruit consumption, we first explain the meaning of consumption. The data collected in the previous section is fruit production. According to the data that can be found, total production $=$ yield + imports - exports, in order to simplify the problem, we only consider the domestic fruit consumption in this article, and calculate the consumption through the wastage rate, total consumption $=$ total output $\times\left(1-a_{1}\right)\left(1-a_{2}\right)\left(1-a_{3}\right)$, where $a_{1}$ expresses as the loss rate from the field to the total market, $a_{2}$ expresses as the loss rate from the total market to the retail market, $a_{3}$ represents as the loss rate from the retail market to the dining-table. Then, it is found that there are many models to solve the prediction problem, each has its own advantages, and the consumption trend of fruit is closely related to the season. Based on the data of fruit consumption over the years, the consumption trend of fruit is analyzed by time series model. In order to verify the rationality of the results, we draw the trend map of fruit consumption year by year, and use the polynomial regression prediction model to test, and get the reasonable prediction data.

The specific fruit consumption data is as follows:

Table-2: Consumption of major fruits from 2006 to 2016 (Unit: tons)

\begin{tabular}{|l|l|l|l|l|l|l|l|l|}
\hline Years & Apple & Pear & Citrus & Banana & Peach & Grape & Red date & Persimmon \\
\hline 2006 & 24774498 & 10375486 & 14536308 & 4365951 & 7110874 & 3922985 & 2785078 & 1804301 \\
\hline 2007 & 26486361 & 11162282 & 16716454 & 4932414 & 7835469 & 4189527 & 2764792 & 2001654 \\
\hline 2008 & 28375083 & 11718993 & 18933545 & 18933545 & 8253201 & 4473968 & 3315308 & 2108072 \\
\hline 2009 & 30118832 & 12346435 & 20475382 & 5588610 & 8691078 & 4967647 & 3875180 & 2203847 \\
\hline 2010 & 31623310 & 13033830 & 21483622 & 6048292 & 9051024 & 5348221 & 4076395 & 2372095 \\
\hline 2011 & 34210670 & 13672421 & 23910283 & 6579347 & 9507218 & 5672605 & 4950754 & 2478397 \\
\hline 2012 & 36592984 & 14778893 & 25727572 & 7311929 & 9894431 & 6595795 & 5370732 & 2657515 \\
\hline 2013 & 37726148 & 14976014 & 26971354 & 7639183 & 10321826 & 7225693 & 5783862 & 2751789 \\
\hline 2014 & 38905544 & 15550444 & 28366012 & 7459952 & 11144164 & 7848646 & 6700976 & 2901065 \\
\hline 2015 & 40512422 & 16185997 & 29725738 & 7886612 & 11807192 & 8551495 & 7367417 & 2948162 \\
\hline 2016 & 41718752 & 16191087 & 30576784 & 8222305 & 12368907 & 8598910 & 7517692 & 3086399 \\
\hline
\end{tabular}

For forecasting, there are multiple methods for forecasting fruit consumption in the next few years. In this article, we will use a time series forecasting model and use historical data to further speculate on future development trends. This article is to predict the trend of consumption in the fruit market. In order to achieve better prediction results, the time series trend prediction method is selected here.

The trend moving average method uses the moving average of the latest actual value as the starting point, and uses the second moving average to estimate the slope of the trend change, and establishes a prediction model:

$$
d_{t}=2 m_{t}^{(1)}-m_{2}^{(2)}, w_{t}=\frac{2}{n-1}\left(m_{2}^{(1)}-m_{t}^{(2)}\right),
$$

where, $d_{t}$ represents the intercept of the predicted straight line, $w_{t}$ represents the slope of the predicted straight line, $n$ represents the average length of each move, and $t$ represents the number of periods.

The prediction model of the trend moving average method is:

$$
y_{t+k}=a_{t}+b_{t} \times k,
$$

where, $k$ denotes the number of trend prediction periods, and $y_{t+k}$ represents the prediction value of the -th period.

Table-3: Forecast of major fruits from 2017 to 2020 (Unit: tons)

\begin{tabular}{|l|l|l|l|l|}
\hline Years & & $\mathbf{. 2 0 1 8}$ & $\mathbf{2 0 1 9}$ & $\mathbf{2 0 2 0}$ \\
\hline Apple & 44170675 & 45922848 & 47675022 & 49427190 \\
\hline Pear & 17280707 & 17896928 & 18513149 & 19129370 \\
\hline Citrus & 32953418 & 34571987 & 36190556 & 37809124 \\
\hline Banana & 8823659 & 9223978 & 9624296 & 10024615 \\
\hline Peach & 12608569 & 13108433 & 13608297 & 14108160 \\
\hline Grape & 9064989 & 9529958 & 9994926 & 10459894 \\
\hline Red dates & 8116309 & 8637074 & 9157838 & 9678602 \\
\hline Persimmon & 3237575 & 3364600. & $t+k 491624$ & 3618649 \\
\hline
\end{tabular}

According to Figure 1, the proportion of bananas, pineapples, longans, and kiwis is $1 \%$, and the proportion is quite small. Considering their living conditions and growing environment, the storage and transportation conditions are 
higher than those of apples, pears and other fruits, so they cannot be regarded as the major fruits. Therefore, the final evaluation of the main fruits is: apples, pears, citruses, bananas, peaches, grapes, red dates and persimmons. We use Matlab to plot the growth trend of the major fruit consumption from 2006 to 2016, as shown in Figure 3. Looking at the figure, the consumption of eight kinds of fruit is increasing year by year, and the growth trend of apple and citrus is obvious over time, while the growth trend of other kinds of fruit is decreasing, especially the change trend of persimmon tends to be stable.

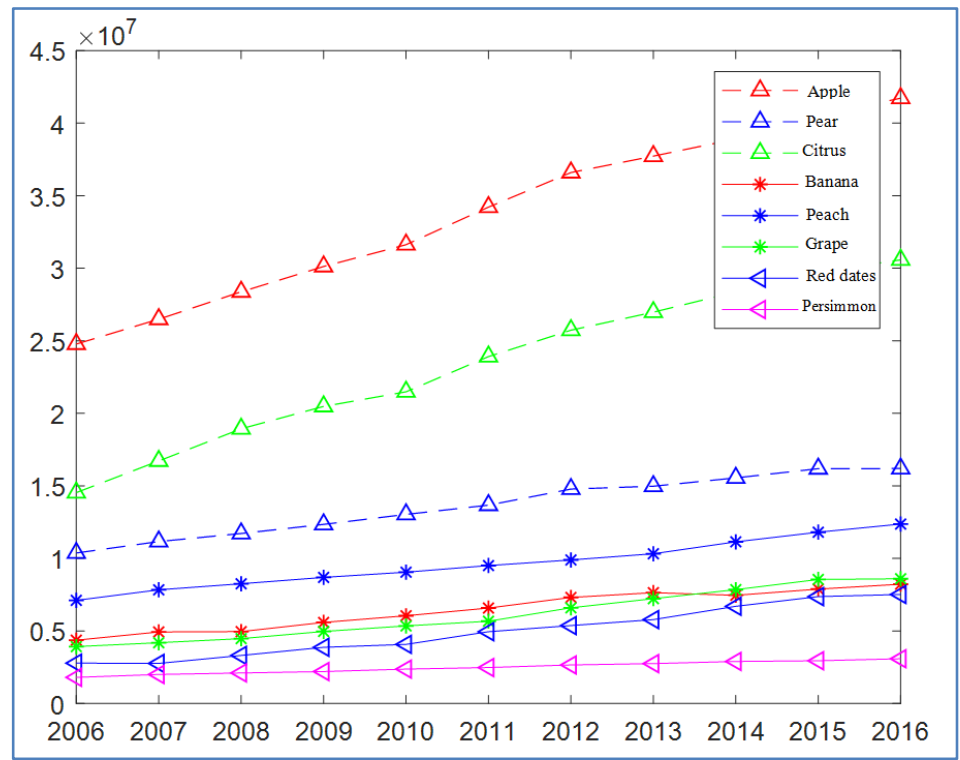

Fig-3: The growth trend of major fruit consumption from 2006 to 2016

Taking Apple as an example to make a polynomial regression prediction model, the results are shown in Figure 4. By observing the graph, it can be seen that the time series prediction results are the same as the regression prediction results, both showing an upward trend, which is basically the same as the actual situation in China. Several other major fruit trend predictions are similar to apples, thus verifying the rationality of the time series trend prediction method.

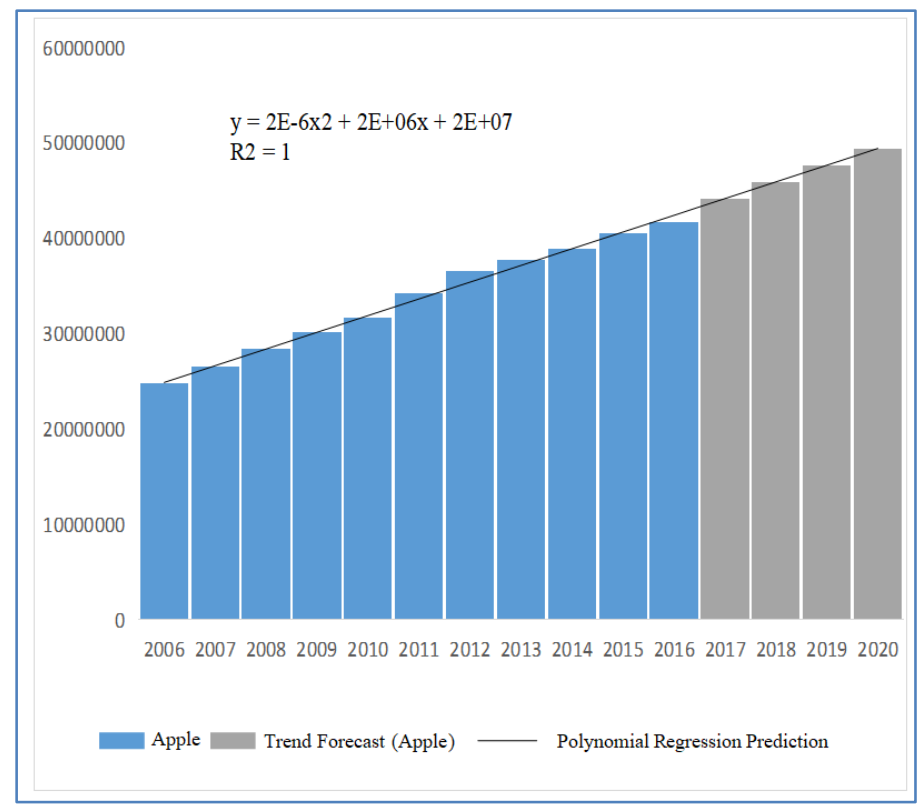

Fig-4: The forecast trend of apple consumption

\section{Conclusions and Recommendations}

In order to achieve reasonable economic development, the state should adjust the production problem according to the annual per capita consumption of fruit products, and also take into account the purchasing power of the people, and consider maximizing the interests of the producers at the same time as the purchase cost is as low as possible. According to the above analysis results, the following strategic aspects of fruit production are proposed: 
(1) To carry out reasonable fruit planting planning and give full play to the advantages of the main producing areas according to local conditions. At present, the rapid development of domestic logistics and preservation technology makes the restriction of fruit transportation smaller and smaller, so reasonable planning and local conditions can make full use of land resources.

(2) To continue the "vegetable basket" project in the agricultural sector [5]. Support the cultivation, processing, transportation and marketing of fruit in many ways, increase income and cut expenditure, and strive to increase economic and policy support to fruit producers from each section.

(3) Promoting high-quality fruit and increasing support for technology in fruit production. Strictly monitor the quality and safety of fruit products. Promote the industrialization of fruit, mechanized production, from each link to ensure fruit quality and yield double harvest.

(4) Increase the export volume of superior fruit varieties and reduce the import volume of scarce fruit varieties. For the superior fruit varieties produced in our country, we can expand the foreign market, increase the export volume, and improve the economic benefit for the fruit farmers [6]. Thereby reducing the impact of imported products on the domestic economic market and stabilizing economic development.

(5) Increase the processing conversion rate of fruit products, prolong the production line and increase the added value. At present, the processing rate of fruit products in our country is far lower than that in developed countries, so we should support and develop the processing industry of fruit products. On the one hand, the industrial chain can effectively prolong the industrial chain and increase the income of fruit farmers, on the other hand, if the fruit production exceeds the market hoarding brought by demand, the industrial chain can effectively digest excessive production and reduce the economic losses of fruit farmers. The optimization of industrial chain can also digest the fruit loss caused by bad weather, thus strengthening the stable development of market economy and protecting the country's name economy.

\section{REFERENCES}

1. Song, M., Wang, Z. (2015). Chinese fruit and vegetable consumption forecast based on gray model. Hubei Agricultural Sciences, 54(12), 3021-3024.

2. Liu, J, Su, Y., Wang, L.(2016). Fruits and vegetables consumption trend prediction and structure optimization under the perspective of balanced human diet in China. Journal of Chongqing University of Technology (Social Science), 36(5), 75-82.

3. Song, C., Li, H., Wu, L.(2017). The analysis of reasonable fruit intake based on the nutritional health angle. Journal of Qiqihar University (Natural Science Edition), 33(4), 83-87.

4. Peng, S., Zhou, Y.(2020). Growth reasons of China's fruit trade: based on the perspective of three margins. Journal of Agro-Forestry Economics and Management, 19(1), 10-23.

5. Ma, L., Lu, Z., Song, N.(2017). On strategies and trend prediction for nutrition development and consumption of fruits and vegetables of residents in China. Journal of Southwest China Normal University (Natural Science Edition), 42(4), 68-75.

6. Zheng, G. (2019). New trend, problems, and suggestions on the fruit import trade development in China. Agricultural Outlook, 12, 139-145. 